\title{
“One Size Doesn't Fit All: Connecting Views of Activism with Youth Activist Identification*
}

\author{
Thomas V. Maher \\ Department of Sociology \\ Purdue University \\ Morgan Johnstonbaugh \\ Jennifer Earl \\ School of Sociology \\ University of Arizona
}

\section{Forthcoming at Mobilization}

\begin{abstract}
Identity is crucial to social movement participation. Existing research examines why active people "avoid" activist identities but has less to say about how active people adopt such identities as if they automatically follow participation. We draw on interviews with high school and college students from a midsize southwestern city to examine how young people make sense of what it means to be an activist, who identifies as such, and why youth are willing - or unwilling - to adopt this label. We find that respondents' conceptualizations of “activists” are critical to (non)identification. Those who see activism as a broad category are more likely to identify, holding constant their level of activity. Those who see activism as a greedy institution, requiring significant substantive fluency, making the issue their primary focus, and willingness to sacrifice, do not, despite their level of engagement. Our findings have implications for identity formation and movement participation more broadly.
\end{abstract}

* This paper is part of a project funded by the John D. and Catherine T. MacArthur Foundation Research Network on Youth and Participatory Politics. We thank Kevin Sharp for research assistance, and Thomas Elliott, Rachel Einwohner, and Charles Seguin for comments on previous versions of the paper. 
Leo is a twenty-four-year-old Latinx college student who is an active member of the Human Rights Campaign, signs petitions, is vegetarian, volunteers with at-risk youth, and readily identifies as an activist, saying I consider myself an activist because "I am trying to look at the world through many perspectives and I'm trying to help others look at the world from many angles as well.” Olivia is an eighteen-year-old Latinx college student who is also highly engaged in activism, signing petitions, participating in organizations, attending protests, and discussing issues. Yet she refuses to identify as an activist. ${ }^{i}$ When asked why not, Olivia explains, “[b]ecause I'm not, I'm too passive. I haven't really obviously made the effort yet to actually get up and do these activist things, and ... I feel strongly about the environment, but, I don't know what comes of that. I don't even know all of the aspects of the environment yet...” Both of these young people are active by any measure, but, reflecting broader differences we found among young people, some active young people claim the identity of an activist while other politically active young people refuse it (for examples, see: Fleming 2014, Lisenby and Edgell 2018).

Understanding who identifies as an activist (and who does not) and how they come to do so (or fail to) is crucial because identity is central to social movement activism (Corrigall-Brown 2011, Polletta and Jasper 2001, Valocchi 2009, White 2010). Activist identities provide participants with a sense of agency and influence on issues, belonging, and connection while working to address a social problem, and they are crucial for sustaining long-term social movement participation (Barr and Drury 2009, Corrigall-Brown 2011, Oliver 1984, Polletta and Jasper 2001). Researchers often treat the identity of an activist as something that would "naturally" follow engaging in activism or from involvement in specific communities; the literature on activist identification reflects this, asking why many engaged individuals avoid identifying as activists rather than asking why, beyond action, people take on this identity. 
Scholarship suggests that some engaged people avoid the label activist because they do not want to be perceived as divisive (Eliasoph 1998), they see the identity—and the political process—as corrupting (Bennett, Cordner, Klein, Savell and Baiocchi 2013, Taft 2006), or they see "being an activist” as something to aspire towards (Bobel 2007, Cortese 2015). Instead of assuming that activist identities follow directly from action, we focus on who adopts an activist identity and what separates them from those who do not.

We focus our questions about activist identification on youth. Young people have been the lifeblood of a number of social movements, including the Civil Rights, Women's, and Immigrant rights movements (Buechler 1990, McAdam 1990, Terriquez 2015). They continually bring new energy to help maintain or expand their reach (Barberá, Wang, Bonneau, Jost, Nagler, Tucker and González-Bailón 2015), and those who identify as activists are more likely to participate in the future (Corrigall-Brown 2011, James and Lee 2017). Despite their importance, youth have historically been treated as lazy and politically uninformed by adults in society and social movement organizations (SMOs) alike (Andersson 2015, Gordon 2007). More recently, youth have also had to negotiate public dismissals of online activism—often utilized by youth (Cohen and Kahne 2011)—as “not enough” compared to true activism (e.g., street protests, sitins, occupations, etc, Diani 2000, Gladwell 2010, Van Laer and Van Aelst 2010), and conservative activists denigrating public activists as “social justice warriors” (Ohlheiser 2015).

In this article, we examine how young people make sense of what it means to be an activist and how that influences whether they adopt that label. We draw on interviews with forty high school and college students from a moderately sized southwestern city to examine how activity (i.e., participation in activism) and constructions of activist identities (i.e., what young people think it "takes" to be an activist) interact as young people decide whether they are 
activists. We find that while activity was necessary for adopting an activist identity, all active youth are not equally likely to identify as activists. Instead, identity adoption turned on how youth conceptualized that label or role. Rather than a one-size-fits-all identity taken off a proverbial rack, we find that youth differently define activism and this has major implications for their adoption of that label. Young people who saw being an activist as an attainable role and did not change their definition to become unachievable when they evaluated themselves (young people we call “achievable activists”) were more likely to identify as activists. By contrast, young people who set a high bar, or raised an achievable bar ever higher when evaluating themselves, were less likely to identify as activists. This unachievable bar was set around three out-of-reach markers: substantial issue fluency, a sense that activist is a primary identity, and a willingness to make substantial sacrifices for a cause. Importantly, we also find consequences for self-identification as an activist: those young people who claimed an activist identity were more likely to report that they intended to continue to engage, whereas those who had been active but did not claim such an identity were far less certain about their future involvement.

\section{Prior Research on Activist Identities}

A substantial body of literature shows that identity is vital for sustaining social movement activity (Horowitz 2017, Polletta and Jasper 2001, Taylor and Whittier 1995). Groups bind themselves together through common interests and experiences, and a sense of collective identity helps foster investment in the group and its actions. Identity also shapes how people see themselves (McAdam 1989), how they contextualize their activities, and their willingness to participate in the future (Giugni 2008). Indeed, one’s self-identification as an activist influences individuals’ willingness to participate in and sustain their engagement in activism like online civic expression (James and Lee 2017) and is often a precursor for deeper activist commitment 
(Oliver 1984, Oliver and Marwell 1992). As Viktor Gecas notes, “values, and the identities based on them, are motivationally important because they are directly relevant to the self's motivational system composed of self-worth, self-efficacy, and self-authenticity” (2000:104).

While it was common in earlier research to focus on very specialized identities—such as adopting the identity of a feminist or environmentalist-more recent literature highlights the differences between collective identity and role-based identities (be it in a movement or a specific organization, Corrigall-Brown 2011, Horowitz 2017), stressing the importance of a more general identification with activism. This fits with public discussions about how activism should be done (Gladwell 2010) as well as debates with scholarly communities about scholar-activists. We examine this more general activist identity, arguing that people active in different movements may have more common views of what it means to be an activist, even if that activism is directed at different causes. This focus also allows us to examine how youth conceive of activism despite their involvement in disparate issues.

The most direct explanation for activist identity adoption is that one adopts such an identity after engaging in activism. However, research shows it is "not automatic" that an activist identity will follow participation (Corrigall-Brown 2011:109), although a leftist ideology, and, to a lesser degree, past participation may be associated with adoption (Corrigall-Brown 2011). The even softer argument that participation in movement actions, organizing, and events shape selfperceptions, which in turn impacts identity, is debatable too (Rupp and Taylor 1987, Whittier 2010).

Instead of focusing solely on behavior, several scholars argue that it is vital to understand how behavior and values intersect to foster activist identities (Corrigall-Brown 2011, Gamson 1991, James and Lee 2017). Whether it is because an individual comes to "care enough about 
some issue that they are prepared to incur significant costs and act to achieve their goals” (Oliver and Marwell 1992:252), or because a path dependency emerges after engaging in activism for long enough makes an activist identity inevitable (McAdam 1986, Munson 2010, Ruiz-Junco 2011), seminal work on social movement participation emphasizes that activists need to be active and committed for the identity to take hold. Likewise, Michelle Oyakawa (2015) finds that organizations can help to foster activist identity adoption. This concern is also reflected in research on how narratives and culture help strengthen and sustain already established identities (Hunt and Benford 1994, Snow and McAdam 2000).

Some make distinctions about different kinds of engagement and identification. In his qualitative study of activist identities, Daniel Cortese (2015) outlines how activists’ identities vary depending on their own level of engagement and their perceptions of others, identifying three groups_-emphatics, demarcators, and rectifiers in the process. ${ }^{\text {ii }}$ Other studies have focused on how narratives and identity talk shape how activists think about their own biographies (Oyakawa 2015, Ruiz-Junco 2011), and how their class and race backgrounds shape narratives and motives for activism (Naples 1998, Valocchi 2013). However, these studies focus predominantly on established, often older, activists involved in organizations, and, in the process, they focus on how they talk about being an activist rather than how they came to adopt such an identity or what the identity means to them.

Importantly, most of the work on activist identity formation tends to focus on avoiding politicized identities even when individuals are actively and attitudinally committed, reflecting the tacit notion that engagement should drive identification. Individuals avoid activist identities for several reasons. In her work on political talk, Nina Eliasoph finds that many individuals— including many who are politically active_-avoided political discussions or identities in fear of 
being perceived as “divisive” by others (Eliasoph 1997, Eliasoph 1998). Other work finds that people disavowed or avoided political identities because they wanted to preserve their sense of political efficacy and idealism by disassociating themselves from the corrupting influence of politics as usual (Bennett et al. 2013, Naples 1998, Taft 2006). For some, the decision to evade an activist identity was shaped by their race and class position (Naples 1998).

While some disavow politics to avoid the negative implications of an activist identity, other scholars argue that being identified as an activist is something honorable and worth aspiring toward. In the process of describing activism as an aspirational goal, activists draw a distinction between "doing activism” and "being an activist” (Blackstone 2004, Bobel 2007, Chalhoub, Ciavattone and Wetzel 2016). Horowitz (2017) refers to this as "role-based" activism. Distinguishing between action and identity in this way raises the expectations for identifying as an activist to require extraordinary action and commitment. Chris Bobel argues that "the conception of activist is anchored in key values of humility and rigor expressed as a 'perfect standard,'” and this standard "places the esteemed identity activist out of reach for many social movement actors who deem themselves unworthy," leading few of Bobel's respondents to identify as activists (2007:150). More recent work contends that young people find a middle ground between "being” and “doing” activism by emphasizing becoming activist, but this work still treats an activist identity as aspirational (Taft 2017). Put another way, activist identities may be driven by how an individuals' behavior holds up against broader cultural and historical expectations of what an activist should be than a grounded assessment of their behavior.

While we know a considerable amount about how identifiers behave after adopting the label and who does not identify as an activist, we know relatively less about who adopts the label and the early moments of that identification or how this process works for younger people. 
Scholarship shows that behavior and belief are necessary but not sufficient drivers of identity, with many who fit these characteristics still not identifying as activists. But, as prior work (Cortese 2015) shows, how potential participants conceptualize what it means to be an activistis it inspirational (Bobel 2007), is it corrupting or contentious (Bennett et al. 2013, Cortese 2015) - may play just as much of a role in activist identification by shaping who is open to identifying as an activist. Indeed, those who see activist identities as accessible will be more likely to adopt the identity. We bring this work together to ask: to what extent is behavior necessary and/or sufficient for youth to adopt an activist identity; what does it mean to youth to be an activist; and how do definitions of activism—particularly how respondents set expectations — shape activist identity adoption? We expect that behavior is necessary but not sufficient. Rather, we suspect that young peoples' understanding of what activism is and what it means to be an activist plays a significant role in identification.

\section{Why Do Activist Identities Matter?}

Prior research suggests that whether individuals adopt general activist identities has implications for future participation. Catherine Corrigall-Brown finds that "it was participants' self-definition as an activist that predicted their propensity to sustain participation and not permanently disengage from social movements” (2011:116, see also: James and Lee 2017). Others find that activist identifiers may be more open to future political engagement in the longrun, acquiring skills, and developing a sense of agency from their activism (Giugni 2008). In the more immediate term, individuals who adopt activist identities may be more open to engaging in the behavior-i.e. engaging in political discussion, participating in events, or signing petitionsthat they associate with the "role" of being an activist (Horowitz 2017, Stryker 2000).

Identity formation may be particularly important for youth. Youth who are engaged in a 
broad range of political activity are more likely to be involved in politics as adults (Andolina, Jenkins, Zukin and Keeter 2003) and youth who self-identify as activists are more willing to engage in online civic expression and sustain a stable level of activism over time despite encountering risks and challenges (James and Lee 2017, White 2010). Young people are also responsive to family and friends (Maher and Earl 2017) and may be more susceptible to being steered away from activism despite growing interests in politics. However, self-identifying as an activist encourages ongoing engagement, even when participants encounter risks or challenges, and slows or prevents permanent disengagement (Corrigall-Brown 2011, James and Lee 2017).

Further, youth participation is important for the long-term vitality of SMOs (Earl, Maher and Elliott 2017), and understanding youth activist identity formation may be key to understanding activism in the future as youth engage in more individualistic and non-institutional forms of political behavior often outside of organizations (Earl, Copeland and Bimber 2017, Fisher 2012). Indeed, if one wanted to forecast the healthiest conditions for future social movements, it would be an environment in which young people are encouraged to see themselves as activists and they carry dispositions for engagement forward, sustaining a commitment to engagement into their adult years. Although we do not have longitudinal data, as discussed below, drawing on this literature, we examine whether there is evidence from our study to support the finding that identity impacts the likelihood of future participation.

\section{Data and Methods}

We draw on structured interviews with forty high school and college students to understand how youth view activism and interpret their own actions (Weiss 1995). We set out to interview youth about their feelings about political engagement; how they engaged, and why they chose to engage (or not engage). We identified potential respondents using a non-random 
sampling strategy. Political engagement can be taboo, particularly for youth (Gordon and Taft 2011, Henn, Weinstein and Wring 2002). We address this by explicitly inviting all youth (i.e. politically active and politically inactive youth) to participate.

We sought respondents who were willing to talk about their political participation or why they chose not to participate and what they thought about participation more broadly. We see this as a major advantage of our sampling strategy since prior research has focused extensively on high-engagement activists and adults (Bennett et al. 2013, Bobel 2007, Cortese 2015, Taft 2006). Focusing on a broader range of engagement offers more insights into the pervasiveness of definitions of activism, the effects of these definitions, and access to methods of differences since non-participants and less active youth can be compared to active youth.

The high school and university are both public schools located in a moderately sized southwestern city. ${ }^{\text {iii }}$ College students were recruited in the summer of 2014 using advertisements posted on university listservs and websites. High school students were recruited in the spring and fall of 2015 with flyers distributed during History and Government courses (required courses for upper-level students) and lunchtime information sessions. Interested youth were interviewed by a project manager or an undergraduate interviewer using a structured interview design outside of the school. ${ }^{\text {iv }}$ Each participant received a twenty-dollar Amazon gift card for participating.

Both schools are diverse economically and ethnically, reflecting the broader city population. We relied on the diversity of the schools we were recruiting in, versus purposive sampling, to ensure a diverse respondent pool. In the end, forty-five percent of our college respondents identified as white, thirty percent as Latinx, twenty percent as multi-racial, and five percent as Asian. Fifty-four percent of our high school students identified as white, thirty-five percent as Latinx, and the remaining ten percent as Asian, African-American, or Native 
American (for more details about our sample, see Maher and Earl 2017). ${ }^{\mathrm{v}}$

We focus on the similarities between high school and college respondents. This approach follows previous research on youth political engagement by treating high school and college together and conceptualizing youth as ranging from fifteen to twenty-five (Andolina et al. 2003, Elliott and Earl 2019, Kahne and Bowyer 2017). Sampling high school and college students offers insights into two different groups at two stages in the process. It also allows high school students to speak to concerns that are salient in the moment but may be overlooked in retrospect. The flow of the interviews and experiences shared complicates comparisons between high school and college students because the interviews, and the interview protocols, invited participants to talk about their political engagement across their lives. Many college students discussed their experiences in high school and college. Moreover, since our sample size is also somewhat small, any comparison between high school and college students would be limited. By focusing on the sample as a whole, we are able to highlight common perceptions of activism.

Completed interviews were transcribed and topically and analytically coded in Atlas.ti. Two of the authors then qualitatively coded each interview to assess the respondents' level of engagement, and their perceptions of activism. Respondents' level of engagement (coded as high, medium, or low) was determined by the frequency of participation in online and offline activism (i.e. participating in protests, boycotts, or SMO events, circulating or signing petitions, etc.). High engagement respondents participated frequently (i.e., it was a regular part of their everyday lives). Low engagement respondents rarely, if ever, participated. Moderately engaged respondents either used to participate frequently and have slowed down or stopped doing so, or participate in spurts but not long enough for it to be described as a regular part of their lives. Interviewers also asked how respondents defined activism, whether they saw their actions 
as a form of activism, and, for those who answered no, whether they considered particular actions activism. ${ }^{\mathrm{vi}}$ We started by assessing each respondents’ answer to these questions as well as their broader discussion of activism, politics, and identity. Two of the authors then identified emergent themes in the respondents' answers. ${ }^{\mathrm{vii}}$ After identifying emergent themes, the authors grouped respondents by their level of activism and self-identity, and iteratively re-immersed themselves in the respondents' answers to understand how non-active and active youth understood activist identities and why some adopted one while others did not.

\section{The Insufficiency of Action for Activist Self-identification}

Our respondents highlight the complex relationship between youth's actions, their cultural and historical expectations, and their understanding of what it means to be an activist. We find that three quarters (thirty) of our sample of forty high school and college students had engaged in some form of activism. Respondents attended marches, donated money, signed online petitions, hung posters, joined groups, helped spread online petitions, and worked to raise awareness about a wide range of social and political issues online and offline. While many of these respondents moved in and out of "doing activism," based on the volume and type of their actions, over a third of all respondents (fifteen) were highly engaged in activism. These youths regularly participated in activism, were members of organizations, donated money, shared and engaged with issues, and, in some cases, held leadership positions in activist organizations.

Despite this level of activity and engagement, only eight of our respondents selfidentified as activists and an additional four did not self-identify as an activist but acknowledged that others may see them as one. None of our inactive respondents volunteered self-identities as activists, suggesting that action was necessary for an activist identity. ${ }^{\text {viii }}$ However, participation was not sufficient for adopting such an identity: while all of the respondents who identified as 
activists had participated in some form of activism and were highly engaged in one or more issues, many of the highly engaged respondents refused to identify as activists. For instance, Francine, a twenty-two-year-old multi-racial college student who regularly volunteers and petitions door to door for a national environmental organization, is engaged with transgender issues, and signs petitions, emphatically rejected an activist identity even after the interviewer pointed out her environmental work because she is "just bottom rung support."

\section{What Makes Someone an Activist?}

We find that the primary factor that distinguishes the youth in our sample who selfidentify as an activist from those who do not was how they conceptualized what it means to be an activist. Respondents offered a range of definitions for being an activist that touched on everything from how they participate to self-identification to the outcomes of their efforts. As we discuss in the next section, those who identified as activists offered—and stuck to—considerably more open and accessible definitions of what it means to be an activist. ${ }^{\mathrm{ix}}$ In contrast, regardless of their level of engagement, the respondents who did not identify as activists drew on a common set of themes: issue fluency, the primacy of the action in their lives, and the willingness to sacrifice to explain why they were not an activist, as discussed more below. One group of young people who did not identify as activists despite being active rejected the label by setting a high bar for all when determining what it would take to identify as an activist; we call them high bar setters. A second group, who we call self-minimizers, offered more accessible descriptions of activism for others, but then raised the bar for themselves. We do not discuss further below the six respondents who were not politically engaged and simply noted their politically disengagement in explaining their lack of identification or did not elaborate on why they rejected the activist label. 


\section{Young "Activists" Believe in Achievable Activism}

Existing work suggests that girls handle the distinction between “doing activism” and “being an activist” by thinking about themselves as "becoming an activist” (Taft 2017). This was not common in our study. Only one of the eight young people who self-identified as an activist fit this notion: Carmen, who "sometimes" considers herself an activist, explained that she is an activist when she is doing activism. None of the active young people denied an activist identity by saying that they were only becoming an activist.

Instead, the other seven young people who self-identified as activists did so by defining what it means to be an activist in broader and more accessible ways. All seven were highly engaged but in contrast to the similarly active high-bar setters and self-minimizers described below, all seven defined activism in broad strokes with loose requirements that typically focused on helping their community and were willing to apply those definitions to themselves. Teresa, a fifteen-year-old white high school student, simply told the interviewer that, "What I think of is in the name active, I guess you can say. I would think that being active in like your community, I guess, doing things that matter really." Similarly, Quinn, a highly engaged twenty-two-year-old white college student who attends political marches, volunteers with Planned Parenthood, signs petitions, and has attended protests in the past defined activism as:

"Being mentally involved in whatever cause you're thinking about. You may not be an outspoken activist, but you can -- if I support environmentalism, I might compost at home and recycle and whatever, but I might not post about it all the time on Facebook.”

When asked whether she was an activist, Quinn agreed “[b]ecause [I have] worked in grassroots organizations. Because I care. I think anybody who really cares can consider 
themselves an activist.” Some “achievable activists” adopted the label more reluctantly. For example, Gwen is a high engagement twenty-year-old white college student who has attended Take Back the Night events, donates money, and helps distribute online petitions. She explains that being an activist means "that you're somebody who genuinely cares about the issues and is trying to make a difference in the world that is positive." Gwen sees herself as an activist, but she still feels she could do more. "Because I feel like I would be more of an activist if I did a lot more offline stuff. So, yes, I consider myself an activist, but I kind of consider myself more of a like convenient timing activist sort of thing." For both women, activism is broad and accessible. It's being “mentally involved” in creating change, or it is trying to make a difference however you see fit.

\section{Setting the Bar Out of Reach}

In contrast to the achievable activists, fourteen of our respondents-including four high engagement and seven moderately engaged respondents-defined being an activist in ways that were unachievable. For these respondents, being an activist meant passing a bar of preconceived requirements; it was not an aspirational identity (i.e. something that youth could achieve if they chose to work for it; Bobel 2007) or a way to distinguish themselves from traditional politics (Taft 2006). Respondents would often refer to the fact that they did not meet the specific criteria that they felt was necessary to identify as an activist, noting that they felt they were not fluent enough, not committed enough, or not willing to sacrifice enough to identify as an activist.

\section{Fluency}

Several respondents indicated that they were not activists because they were not fluent enough in the causes that they cared about. For our respondents, being an activist meant being able to discuss the issue, the historical and political context, $\underline{\text { and }}$ its future policy implications. 
For example, Will, a moderately engaged seventeen-year old Asian high school student explained that he did not feel he was an activist because he did not know enough, stating: "I would define activist as someone who is really active on a certain topic, like everything about it, they know what started this, what happened, what might happen, you know, all the outcomes." Olivia, a highly engaged respondent, also emphasizes the role of knowledge for activist identity: "Someone who shows their full-fledged support and is willing to do their part and to -- making something happen. I believe they have a good background knowledge of what they're supporting, and I think that they are willing to put in whatever they can to do that. So that's someone that legitimately knows what's going on. I don't know what goes on, so -- I don't know yet.”

Respondents' emphasis on fluency fits with the existing literature’s descriptions of what it takes to be an activist. Eliasoph found that the "standards for technical knowledge required for citizenship were impossibly high” just to talk about politics for the respondents in her study (1998:140), and activists in related studies have expressed similar sentiments (Cortese 2015, Taft 2017). It is not surprising that this is pronounced among youth given the false assumption that they are politically apathetic, naïve, and need to be "brought up to speed" to participate in politics (this is referred to as the "deficit” model, Gordon 2008, Henn et al. 2002). Like prior studies (Gordon 2007, Taft 2017), perhaps part of being an activist for some youth in our study requires demonstrating an understanding of issues that "makes up for” their age.

\section{The Primacy of Commitment}

A second aspect of the bar for activism that young people referenced was the sense that they needed to make activism the primary focus in their life. For respondents, being an activist meant activism was their primary or preeminent focus. Activists are expected to stay engaged 
with issues for long periods, take on important organizational roles, and engage in offline activism. We hear this in Olivia's emphasis on "full-fledged support" in her quote above as well as from respondents like Carmen, a twenty-year-old Latinx college student who ran an activist organization. Carmen resisted fully identifying as an activist because the cause (health) was not her primary focus:

"I think it has to be almost their entire life. That's what I feel like sometimes. Like even now with like [organization], I feel like I will be an activist sometimes when I’m doing it right then, but like right now, I don't feel like an activist. I just feel like I'm part of an activist group. And then when I'm doing it, I'm an activist. I don't feel like it's an all the time role unless I'm doing it all the time."

Carmen describes being an activist as a twenty-four seven role and differentiates herself from true activists because she balances her leadership role in an activist organization with other roles and responsibilities. Similarly, Danny, a moderately engaged twenty-year-old Latinx college student participated in protests and online campaigns in high school but recently reduced his engagement because he was not willing to commit to offline activism:

“[Participating in protests and wanting to go to med school] doesn’t -- it doesn’t mix entirely too well, but that's one of the reasons why if I did get involved in something, it would have to mean a lot to me, and I'd have to do a lot, because it's also now part of your identity, especially with the online thing -- or with everything being online and all this information being online. . . But once you go outside and actually join a protest rally and actually do something, it -- it's a whole other level that a lot of people will notice, if they found out that you did that. So -- but then you're almost kind of identified with that idea, which can go 
good and can go wrong.”

For Carmen and Danny, activism had to be the most important activity if they were to identify as an activist. Whether this means that it had to be a "master status" (Charmaz 1994) or the most important identity in a hierarchy (Stryker and Serpe 1994), it still meant that they felt they had to prioritize activism over their school, career, and social life. Several other respondents echoed this sense that a true activist makes activism their primary focus, and their willingness to do so is most evident through their participation in offline activism. This finding fits with prior work on activist identities (Blackstone 2004, Horowitz 2017, Taft 2017). For example, one study concludes that even though many of their respondents embraced an inclusive vision of activism, “being an activist seems in these students' minds to require a singularity of focus, purpose, and time” (Chalhoub et al. 2016:304). Yet, where these prior studies see dedication as aspirational, we find that many young people were dissuaded by the sense that they must always do more. Sacrificing for the Cause

Finally, respondents explained that they did not see themselves as activists because they were not sacrificing enough. For many respondents, being an activist meant sacrificing significant time or being willing to get arrested for their cause. For Nina, a moderately engaged 20-year-old Latinx college student, being an activist requires “devoting a significant amount of time to whatever you're trying to make happen and trying to change something;" she rejects the identity because "compared to other activists[,] the amount of effort I put in is like nothing." Several respondents also indicated that being an activist meant accepting the risk—or the inevitability—of getting arrested. For example, Ben, a twenty-five-year-old bi-racial college student, suggested that jail is not just a requirement; it is an inevitable outcome of an activist identity: 
"Just because I feel like a lot of things get swept under the rug, and the first thing that I would do is remove the rug, and I would have a dust blower, and I would make people breath all that dust that they were hiding... They would lock me up, throw away the key until I got out somehow.”

In addition to discouraging some respondents from identifying as activists, these concerns about the risks of protest also prevented others from participating in offline activism altogether because they saw it as particularly risky, especially the possibility of arrest.

Existing scholarship has long emphasized how activists, influenced by prior movements’ sacrifices (Gould 2009, McAdam 1990), feel they must be willing to give up time, resources, and reputation and take on considerable risks (injury, arrest, financial well-being, etc.) in pursuit of social and political change (see also: Cortese 2015:218-19). Bobel quotes an activist who explains that to be a "real activist ... you have to live outside the norm. [real activists] give everything up. You know, electricity, kids, marriage” (2007:155). Although Bobel reported that respondents knowingly laughed at this notion, it highlights, if not exaggerates, this perception. Such sentiments are evident in journalistic accounts of activism too. In his widely circulated piece on the topic, Malcolm Gladwell states that online activism is what people do when they are "not motivated enough to make a real sacrifice" (2010).

Respondents who set a high bar for activism universally refused to identify as activists— regardless of their personal engagement—and explained their rejection of the identity by drawing on similar themes of fluency, primacy, and sacrifice. While these themes may overlap in important ways, they each play a role in how youth conceptualize what it means to be an activist. But, they do not mirror the aspirational qualities of prior findings. Self-Minimizing: Holding Yourself to a Higher Standard 
Five high engagement and three moderately engaged respondents initially offered broad or achievable definitions of activism, but, when asked if they are an activist, raised the bar to a higher level and refused the identity. These self-minimizers were open to achievable activism for others, but they cited the same themes high bar setters referenced—fluency, primacy, and sacrifice — when considering whether they themselves were activists. For example, Eric is a sixteen year old white high school student who participates in a lot of online activism and defines an activist as "anyone who's willing to give up their time for a cause they believe in. And that's not always good, but, to me, activis[m] has another good connotation." Although he initially defines activism in achievable terms, he demurs when asked if he is an activist, highlighting how activism is not his primary focus and he has not sacrificed enough.

"I don't know. When I think about it in my -- in my head, I'm -- I think, that's not me. But I could see -- I could see maybe you could say, sure, I'm an activist because I sign petitions, but I think, to me, I haven't earned the title of activist. Like I haven’t taken next steps beyond petitions. All I do is put my name on something. And other people will like dedicate parts of their lives to go to foreign countries and help people. Like I'm not -- I'm not deserving of the term activist." Those who engage in offline activism reset the bar too. For example, Francine, introduced above, defines activism in broadly inclusive terms, stating that "[i]deally, an activist is someone who raises awareness for things and controversies that they feel are important and need to change, and takes action over them." Francine’s actions easily meet the expectations she outlines, but she immediately rejects the notion of being an activist. As she explains, her “immediate reaction to most things political is to just, whoa, run for it, because it's usually just so nasty, I don't want to deal with it.” In this sense, they see activism in an abstract, achievable 
light, but, in practice, they perceive it as divisive and something to avoid (Eliasoph 1998). For Francine, an activist must be committed enough to deal with the "nastiness" of the political process.

Similarly, Isabelle is a twenty year old Latinx college student who has participated in health advocacy and women's organizations and volunteered for political campaigns. Like Francine, she defines activism broadly as "actively doing something to change something else, or to change either people's minds or a policy or just bringing about change in some way, shape, or form,” but when asked if she is an activist she responded, “I don’t think I do anything to push for change.” Clearly, Isabelle is involved in activities that help to change people's minds and/or public policies, but, like Francine, she is unwilling to see her own actions in this context.

In sum, the young people who adopted the identity of an activist largely did so because they set broad and accessible definitions of activism and then adopted them. In contrast, high-bar setters and the self-minimizers established high, often quixotic, expectations for activismespecially when they were evaluating their own behavior. For these self-minimizers, activism is broad and achievable as an abstract concept, but they use the same cultural themes of fluency, primacy, and sacrifice that high-bar setters use to distance themselves from an identity that they see as divisive, or to explain why their actions will never reach the levels necessary to genuinely identify as an activist. Notably, although many respondents acknowledged similar cultural touchstones in their definitions of an activist, the respondents who were most likely to selfidentify as activists were also those who were least likely to draw on those touchstones.

\section{What Structures the Creation of (Un)Attainable Views of Activism}

Given that we find that an achievable cultural definition of activism is critical to selfidentification for the youth we studied, it is important to ask whether there was clear evidence 
from our interviews about where that achievable definition comes from. For instance, perhaps who identifies as an activist and how they define what an activist is may be influenced by the respondents’ demographic or personal characteristics (Naples 1998, Valocchi 2013).

We first assessed this possibility by evaluating whether activist identities varied by respondents' gender or race. We looked at basic frequency tables and chi-square distributions to see if there were gender differences in who considers themselves an activist. We find suggestive, but not definitive, statistical evidence for a relationship ( $(\mathrm{p}=.06)$. Given the small size of our sample and that seven of the eight respondents who identified as activists were women out of twenty-one women interviewed, we think future research should try to understand this potential relationship better, although it is not clear from our interviews why girls and young women were so much more willing to define activism flexibly and broadly. For instance, we find no gender differences in online activism and, in contrast to previous work (Dodson 2015), the young women we interviewed were significantly more likely to have participated in offline activism $(\mathrm{p}=.001)$. Instead, perhaps girls and young women are simply more practiced at broadly defining categories so that they can fit into them. Girls and young women, for instance, have to broadly define who is good at male-dominated subjects, activities, and professions if they want to see themselves in those fields. Even if the actual mechanism allowing girls and young women to define activism more flexibly is altogether different, we hope future research focuses on this difference to both replicate and explain it.

We follow the same process to look at whether racial differences help explain activist identification. We find that there are no significant differences in activist identities across racial groups ( $\mathrm{p}=.57)$, nor does a more qualitative assessment of the spread across cells indicate a pattern. Six of our activist identifiers were white, but eighteen of our respondents were white so 
it is impossible to view this as a causal finding drowned out by the small sample size.

We also assessed alternate measures of engagement, focusing on participation in online and offline activism. Critical readers may believe that action is really responsible for identification, but one must focus on the "right" kind of action to see this. We do not find evidence for this argument. Self-identifiers, who tended to have broader and more flexible views of activism, were not significantly more likely to participate in online activism ( $\mathrm{p}=.461)$. Of those who engaged in offline activism, more did not identify as an activist than did, suggesting that it was not simply that those who engaged offline would see themselves as activists.

Another explanation for differences in activist identity adoption may be where individuals are in their micromobilization trajectories. Individuals who are just getting involved may be more hesitant to identify as activists compared to more seasoned participants, and those who are invited by others may be less willing to identify than those who pursued activism on their own volition. Previous studies have focused on established activists' sense of identity (Bennett et al. 2013, Bobel 2007) and biographical narratives of activist identities (Oyakawa 2015, Ruiz-Junco 2011). When we explore our data, we find no clear patterns. All of our respondents are early in their activist careers, and they describe getting involved in activism in several different ways. There is some evidence that activist identifiers were more "intrinsically" motivated to participate than non-identifiers and that highly engaged non-identifiers were more likely to express other interests (i.e. activism was not their top priority) or to point to their friends as the "true" activists. But these differences may be as much the result of identifying as an activist as they are the explanation for the disparate identities. We also find that three of the eight identifiers were high school students, indicating that a straightforward distinction between high school and college is also not the answer for who identifies as an activist. 
We also examined whether organizational connections or strong network ties to others engaged in activism shaped whether someone had an achievable view of activism and applied it to themselves. Neither factor mattered for activist self-identification. Only two of the seven respondents who identified as activists were in some kind of activist, advocacy, or fan activist group. Five of the ten respondents who had politically active friends or acquaintances identified as activists. Two of those identifiers only discussed their friends in passing, raising questions about their degree of influence. Further, three of the five non-identifiers who had active peers discussed how their peers' activism made them feel less active by comparison. Although prior work does suggest that organizations can foster activist identity formation (Oyakawa 2015) and that social networks are important but not necessary for participation (Klandermans 2004), these results clearly convey the need for further work on their relationship with identity formation.

We also assessed whether there were any definitional elements (e.g., fluency) that were particularly impactful. Although we discuss all three above, we tried to determine whether any singular element was particularly impactful and/or whether it was clear from the interviews how respondents developed each of these component views about activism. Unfortunately, our data did not point to a preeminent factor and also did not show unique and identifiable pathways to developing these elemental views about activist identities.

Aside from a potential influence of gender, there were no clear indicators for why some adopted more achievable views of activism. We can ask an alternative question though: where did high bars for activist identities come from? Our interviews suggest that cultural archetypes of activists are important and that activist identities are constructed from cultural examples and archetypes, not made ad hoc from movement to movement. Leaving aside the historic mythmaking (Morris 1986), Eli, a twenty-year-old white college student, discussed Edward 
Snowden's whistleblowing and Rosa Park's involvement in the Civil Rights movement as examples of how it takes "being in the right place at the right time" to be an activist and how he would not have the same opportunity to become an activist:

"I also think being in the right place at the right time allows you to be an activist. Like probably a clichéd example is Rosa Parks just being in the bus at the right time in the Montgomery boycotts. That instance allows her to be an activist that actually can engender change. I'm not in a situation now where I'm actually going to be able to do that."

Broader research suggests that engagement is viewed in comparison to a culturally constructed, romanticized notion of the 1960's activism. The activists that Bobel interviewed specifically cited aspiring to examples of activism from the 1960-70s (2007:155). Chalhoub et. al (2016) and Cortese (2015) describe activists using historical comparisons as a part of their selfreflections on what an activist should be. Activists in Oyakawa’s study (2015) were directly encouraged to compare their narratives to famous civil rights leaders (2015:409). Finally, Gladwell's popular piece explicitly compares online activism to the Woolworth's sit-ins (2010). Some forms of activism — particularly protests, sit-ins, and occupations where there is a risk of injury or arrest (Diani 2000, Van Laer and Van Aelst 2010)—are more likely to be championed than the day-to-day consensus mobilization, community building, and organization of activities that are crucial for creating lasting political change.

These historical archetypes and notions of "true" activism add up to a revered image of an activist. As Cortese summarizes, activists are seen as "deeply courageous, full of conviction, and having deep dedication to the cause... activists risk their lives and reputations to follow their convictions with an ambition to transform the world” (2015:218, see also: Taft 2017). This aligns 
very closely to the high bar for activism we saw many youth adopt, and to the specific criteria of fluency, primacy of commitment, and sacrifice they discussed. We argue that individuals identify similar expectations for activism because they share similar historical icons and touchstones, making it difficult to see one's actions as worthy, effective, or authentic enough to count as activism too. While cultural figures like Parks, Snowden, and the Civil Rights movement may serve as inspiration for some, they may be a detriment to activist self-identification among youth who are contending with preconceived notions of their interests (Gordon and Taft 2011) or critiques of their preferred or available repertoires of contention.

The ambiguities that surround the definition of activist contribute to our explanation for why not all highly engaged respondents identify as activists. In the absence of a hard or fast definition of what an activist is, people, particularly youth, flesh out the definition based on the clearest examples they can find. The elements that our respondents cited when describing activists were repeated by many and these largely matched the descriptions of activists that may be seen in history books, movies, and traditional media that have criticized online activism as slacktivism and praised offline activism as the one, "true” form of activism. Why some were able to loosen the grip of these cultural definitions of activism, though, remains an open question. Although we are unable to uncover clear explanations for why some young people developed achievable definitions of activism and were willing to apply those standards to themselves, future research is now better positioned to investigate this, particularly by focusing on gender and the embrace of particular criteria such as fluency, primacy, and sacrifice.

\section{How Does Adopting an Activist Identity “Matter”?}

As we discussed earlier, existing scholarship establishes a connection between activist identification and a heightened likelihood of continued engagement. Unfortunately, our 
interviews were a single cross-section and there are no prospects for re-interviewing, limiting our ability to demonstrate the longitudinal effects of these definitions. However, while far from conclusive, our interviews do offer interesting suggestions about the potential effects of selfidentifying as an activist and their intentions for future participation. ${ }^{\mathrm{x}}$ For this section, unless otherwise noted, we focus exclusively on high engagement respondents future intentions. ${ }^{\mathrm{xi}}$

When asked about their willingness to participate in the future, achievable activists were more open to future participation. For example, when asked if he would continue to sign petitions in the future, Leo, a highly engaged twenty-four-year-old Latinx college student responded:

"Yeah, for sure. Because, now that I'm just getting myself more involved with a lot of global issues, I think that I would like to turn my art history degree into something that's fruitful and turn it into something where I can take on a lot of issues."

Gwen was even more unreserved. She stated she would gladly sign any petition that they found on immigration and border issues. When asked if she would continue to participate in online and offline activism, she responded "Yeah, I hope so. I would like to continue to be an activist in all [these] areas, and to be a better one." She also added, "I'd like to start attending some immigration rallies, if I can." Similarly, Teresa responded, "Yeah, I think so. If it’s something I feel strongly about, yeah" when asked if she would ever consider joining a demonstration or signing a petition. She was especially open to online activism because "it's just one click away, so it doesn’t really take that much time to just get the word out.” One exception was Paul, a twenty-two-year-old white college student, and the only respondent who set an achievable bar but did not identify as an activist. He indicated that he would probably not participate in the 
future because he was not sure if online activism was effective, but he was still open to participating in the future, "if I care about it, and I actually think it might have an impact."

In contrast, the willingness of the majority of highly engaged "high-bar setters" and "selfminimizers'” to participate in the future was much more contingent. For instance, when asked about the conditions needed for her to participate in the future, Olivia, who participated in a range of on and offline activity, explained that it had to be convenient for her.

"If it was near my house, if it benefitted me and a lot of other people, like a majority thing, and if it was something I was interested in or had a connection to.

But I haven't come across anything like that yet.”

Similarly, Tim responded "Of course. If I see that I can be of help to people, yeah" when asked if they would be willing to participate in online activism in the future. Ben, who was more moderately engaged, explained that he would be willing to participate in activism again if lots of people cared about the issue and if enough people were in the streets they could ensure some level of anonymity. Indeed, among the twenty-eight total "high bar" and "self-minimizer" respondents, only two respondents were unequivocal "yeses.” The rest answered some mix of “maybe," "probably," and "probably not."

In sum, there is some potential evidence that activist identifiers will be more willing to participate in the future than non-identifiers. This supports Corrigall-Brown's argument that selfdefinition helps predict the propensity for future participation (2011, see also: Barr and Drury 2009, James and Lee 2017). It also suggests that accepting the "role" of an activist (Horowitz 2017, Stryker 2000) primes an individual to visualize their future behavior and engagement.

\section{Conclusion}

We find that action is necessary but insufficient for explaining young people's self- 
identification as activists. While the majority of our respondents engaged in some form of political activism, far fewer were willing to identify as activists. Young people who set achievable expectations for activism and did not inflate expectations for themselves were more likely to identify as activists. In contrast, those who rejected the identity set unachievable definitions of being an activist—emphasizing fluency, primacy, and sacrifice—or initially set achievable definitions only to minimize their own activity by reference to these same difficult-toachieve criteria. Although we were unable to uncover a definitive causal explanation for why some young people held achievable views of activism and others set high bars for everyone, or elevated the bar for themselves, we do have suggestive results around gender and the role of cultural activist archetypes that we hope will help drive future research. Our data also supports the existing literature's conclusion that activist identity adoption is consequential for future action, with those who identified as activists saying they were more open to future activism.

These findings make several important contributions to the social movement literature on activist identities. First, they highlight how abstract conceptualizations of an identity are critical to identity adoption versus avoidance. Previous research has highlighted how belief and behavior alone are necessary but insufficient for identifying as an activist (Corrigall-Brown 2011, Gamson 1991, Taft 2017). By defining activism in achievable terms, young participants may help manage expectations for what is required for participation.

Second, these findings underscore the potential perils of excessive standards for activist identities. Youth are already expected to do and know more to overcome perceived political “deficits” (Gordon and Taft 2011, Osler and Starkey 2003), and expecting them to be completely engaged to be an activist raises the cost of entry into activism even higher. Such expectations may deter the infrequently involved from further participation (Eliasoph 1998, Norgaard 2006), 
and the involved from taking pride in their activism (Bennett et al. 2013). Both of these are particularly troubling for movements trying to build consensus mobilization (Barberá et al. 2015, Klandermans 2004). Unattainable definitions may also harm movements in the long run because, while some non-identifiers may participate in the short term, non-identifiers are also more likely to permanently disengage (Corrigall-Brown 2011, James and Lee 2017, White 2010). Indeed, our findings suggest that if people were working toward broader cultural goals of expanding activism and engagement, they would do well to scale back the high expectations for activism; particularly the emphasis on offline activism.

Third, our study design expands our understanding of activist identity formation by focusing on young people's emerging identities. In addition to focusing on young people, we do not focus entirely on committed activists, but study young people with varying levels of actual (dis)engagement and varying connections to the activist identity, which moves beyond prior research on more committed activists.

Future research should explore how activist identities are developed, why active individuals may avoid them, as well as how they affect future participation. How do race, gender, age, and class influence identity formation? Where do definitions of "being an activist" come from? Are they drawn from broader historical examples or do they come from more immediate influences like family and peers? How do social networks and organizations facilitate or deter activist identity formation? Finally, how do emotional reactions to often contested identities like being an activist influence how individuals define being an activist and their willingness to adopt the identity? Answers to such questions will contribute to the literature on activist identity formation as well as the broader debates over whether political inactivity and quiescence is the result of individual disinterest or hegemonic deterrence (Gaventa 1982) or 
more meso-level factors (Auyero and Swistun 2008, Norgaard 2006). 


\section{Work Cited}

Andersson, Erik. 2015. "Situational Political Socialization: A Normative Approach to Young People's Adoption and Acquisition of Political Preferences and Skills." Journal of Youth Studies 18(8):967-83.

Andolina, Molly, Krista Jenkins, Cliff Zukin and Scott Keeter. 2003. "Habits from Home, Lessons from School: Influences on Youth Civic Engagement." Political Science and Politics 36(2):275-80.

Auyero, Javier and Debora Swistun. 2008. "The Social Production of Toxic Uncertainty." American Sociological Review 73(3):357-79.

Barberá, Pablo, Ning Wang, Richard Bonneau, John Jost, Jonathan Nagler, Joshua Tucker and Sandra González-Bailón. 2015. "The Critical Periphery in the Growth of Social Protests." PLoS ONE 10(11):e0143611.

Barr, Dermot and John Drury. 2009. "Activist Identity as a Motivational Resource: Dynamics of (Dis) Empowerment at the G8 Direct Actions, Gleneagles, 2005." Social Movement Studies 8(3):243-60.

Bennett, Elizabeth, Alissa Cordner, Peter Taylor Klein, Stephanie Savell and Gianpaolo Baiocchi. 2013. "Disavowing Politics: Civic Engagement in an Era of Political Skepticism." American Journal of Sociology 119(2):518-48.

Binder, Amy and Kate Wood. 2012. Becoming Right: How Campuses Shape Young Conservatives, Vol. 54. Princeton, NJ: Princeton University Press.

Blackstone, Amy. 2004. "“It’s Just About Being Fair” Activism and the Politics of Volunteering in the Breast Cancer Movement." Gender \& Society 18(3):350-68.

Bobel, Chris. 2007. "'I'm Not an Activist, Though I've Done a Lot of It': Doing Activism, Being 
Activist and the 'Perfect Standard'in a Contemporary Movement." Social Movement Studies 6(2):147-59.

Buechler, Steven. 1990. Women's Movements in the United States: Woman Suffrage, Equal Rights, and Beyond. New Brunswick, NJ: Rutgers University Press.

Chalhoub, Hailey, Domenique Ciavattone and Christopher Wetzel. 2016. "“I Wouldn’t Classify Myself as an Activist” Reflections on Studying Contemporary Student Engagement." Humanity \& Society 41(3):299-312.

Charmaz, Kathy. 1994. "Identity Dilemmas of Chronically Ill Men." The Sociological Quarterly 35(2):269-88.

Cohen, Cathy and Joseph Kahne. 2011. "Participatory Politics. New Media and Youth Political Action." Oakland, CA: YPP Research Network.

Corrigall-Brown, Catherine. 2011. Patterns of Protest: Trajectories of Participation in Social Movements. Palo Alto, CA: Stanford University Press.

Cortese, Daniel. 2015. "I’m a “Good” Activist, You're a “Bad” Activist, and Everything I Do Is Activism: Parsing the Different Types of “Activist” Identities in Lbgtq Organizing.” Interface: A Journal on Social Movements 7(1):215-46.

Diani, Mario. 2000. "Social Movement Networks Virtual and Real." Information, Communication \& Society 3(3):386-401.

Dodson, Kyle. 2015. "Gendered Activism: A Cross-National View on Gender Differences in Protest Activity." Social Currents 2(4):377-92.

Earl, Jennifer, Lauren Copeland and Bruce Bimber. 2017. "Routing around Organizations: SelfDirected Political Consumption." Mobilization: An International Quarterly 22(2):131-53. Earl, Jennifer, Thomas Maher and Thomas Elliott. 2017. "Youth, Activism, and Social 
Movements." Sociology Compass 11(4):e12465.

Eliasoph, Nina. 1997. "“Close to Home”: The Work of Avoiding Politics." Theory and Society 26(5):605-47.

Eliasoph, Nina. 1998. Avoiding Politics: How Americans Produce Apathy in Everyday Life. Boston, MA: Cambridge University Press.

Elliott, Thomas and Jennifer Earl. 2019. "Kids These Days: Supply and Demand for Youth Online Political Engagement." Pp. 69-100 in Digital Media and Democratic Futures, edited by Michael Delli Carpini. Philadelphia, PA: University of Pennsylvania Press.

Fisher, Dana. 2012. "Youth Political Participation: Bridging Activism and Electoral Politics." Annual Review of Sociology 38(1):119-37.

Fleming, Olivia. 2014. "\#Blacklivesmatter: These Two Young Women Rallied 50,000 to Protest Police Brutality in Nyc." Elle, 12/18/2014. Retrieved: 6/5/2018 (https://www.elle.com/culture/career-politics/news/a19701/unmaara-elliot-syneadnichols-millions-march-interview/).

Gamson, William. 1991. "Commitment and Agency in Social Movements." Sociological Forum 6(1):27-50.

Gaventa, John. 1982. Power and Powerlessness: Quiescence and Rebellion in an Appalachian Valley. Champaign, IL: University of Illinois Press.

Gecas, Viktor. 2000. "Value Identities, Self-Motives, and Social Movements." Pp. 93-109 in Self, Identity, and Social Movements, Vol. 13, edited by Timothy Owens Sheldon Stryker, Robert White. Minneapolis, MN: University of Minnesota Press.

Giugni, Marco. 2008. "Political, Biographical, and Cultural Consequences of Social Movements." Sociology Compass 2(5):1582-600. 
Gladwell, Malcolm. 2010. "Small Change: Why the Revolution Will Not Be Tweeted." The New Yorker.

Gordon, Hava. 2007. "Allies within and without How Adolescent Activists Conceptualize Ageism and Navigate Adult Power in Youth Social Movements." Journal of Contemporary Ethnography 36(6):631-68.

Gordon, Hava. 2008. "Gendered Paths to Teenage Political Participation Parental Power, Civic Mobility, and Youth Activism." Gender \& Society 22(1):31-55.

Gordon, Hava. and Jessica Taft. 2011. "Rethinking Youth Political Socialization Teenage Activists Talk Back." Youth \& Society 43(4):1499-527.

Gould, Deborah. 2009. Moving Politics: Emotion and Act Up's Fight against Aids. Chicago, IL: University of Chicago Press.

Henn, Matt, Mark Weinstein and Dominic Wring. 2002. "A Generation Apart? Youth and Political Participation in Britain." The British Journal of Politics \& International Relations 4(2):167-92.

Horowitz, Jonathan. 2017. "Who Is This “We” You Speak Of? Grounding Activist Identity in Social Psychology." Socius 3:1-17.

Hunt, Scott and Robert Benford. 1994. "Identity Talk in the Peace and Justice Movement." Journal of Contemporary Ethnography 22(4):488-517.

James, Carrie and Ashley Lee. 2017. "Speaking up Online: Civic Identity and Expression in the Digital Age." Pp. 119-46 in Social Movements and Media, edited by Jennifer Earl and Deana Rohlinger. Bingley, England: Emerald Publishing Limited.

Kahne, Joseph and Benjamin Bowyer. 2017. "Educating for Democracy in a Partisan Age Confronting the Challenges of Motivated Reasoning and Misinformation." American 
Educational Research Journal 54(1):3-34.

Klandermans, Bert and Dirk Oegema. 1987. "Potentials, Networks, Motivations, and Barriers: Steps Towards Participation in Social Movements." American Sociological Review 52(4):519-31.

Klandermans, Bert. 2004. "The Demand and Supply of Participation: Social-Psychological Correlates of Participation in Social Movements." Pp. 360-79 in The Blackwell Companion to Social Movements, edited by David Snow, Sarah Soule and Hanspeter Kriesi. Maiden, MA: Blackwell Publishing.

Lisenby, Ashley and Holly Edgell. 2018. "'We Are the Voice:' St. Louis Student Leaders Reflect on 50th Anniversary of King Assassination " St. Louis Public Radio, 4/4/2018. Retrieved: 6/5/2018 (http://news.stlpublicradio.org/post/we-are-voice-st-louis-student-leadersreflect-50th-anniversary-king-assassination).

Maher, Thomas and Jennifer Earl. 2017. "Pathways to Contemporary Youth Protest: The Continuing Relevance of Family, Friends, and School for Youth Micromobilization." Pp. 55-87 in Social Movements and Media, Vol. 14, edited by Jennifer Earl and Deana Rohlinger. Bingley, England: Emerald Publishing Limited.

McAdam, Doug. 1986. "Recruitment to High Risk Activism: The Case of Freedom Summer." American Journal of Sociology 92(1):64-90.

McAdam, Doug. 1989. "The Biographical Consequences of Activism." American Sociological Review:744-60.

McAdam, Doug. 1990. Freedom Summer. New York:: Oxford University Press, USA.

Morris, Aldon D. 1986. The Origins of the Civil Rights Movement. New York: Simon and Schuster. 
Munson, Ziad. 2010. The Making of Pro-Life Activists: How Social Movement Mobilization Works. Chicago, IL: University of Chicago Press.

Naples, Nancy. 1998. Grassroots Warriors: Activist Mothering, Community Work, and the War on Poverty. New York: Routledge.

Norgaard, Kari Marie. 2006. "“People Want to Protect Themselves a Little Bit”: Emotions, Denial, and Social Movement Nonparticipation." Sociological Inquiry 76(3):372-96.

Ohlheiser, Abby. 2015. "Why 'Social Justice Warrior,' a Gamergate Insult, Is Now a Dictionary Entry." Washington Post, 10/7/2015. Retrieved: 3/29/2018 (https://www.washingtonpost.com/news/the-intersect/wp/2015/10/07/why-social-justicewarrior-a-gamergate-insult-is-now-a-dictionary-entry/?utm_term=.0fd65cc56249).

Oliver, Pamela. 1984. "' If You Don't Do It, Nobody Else Will": Active and Token Contributors to Local Collective Action." American Sociological Review 49(5):601-10.

Oliver, Pamela and Gerald Marwell. 1992. "Mobilizing Technologies for Collective Action." Pp. 251-72 in Frontiers in Social Movement Theory, edited by Aldon Morris and Carol Mueller. New Haven, CT: Yale University Press.

Osler, Audrey and Hugh Starkey. 2003. "Learning for Cosmopolitan Citizenship: Theoretical Debates and Young People's Experiences." Educational review 55(3):243-54.

Oyakawa, Michelle. 2015. "“'Turning Private Pain into Public Action”: The Cultivation of Identity Narratives by a Faith-Based Community Organization." Qualitative Sociology 38(4):395-415.

Polletta, Francesca and James Jasper. 2001. "Collective Identity and Social Movements." Annual Review of Sociology 27:283-305.

Ruiz-Junco, Natalia. 2011. "“Losing Neutrality in Your Everyday Life”: Framing Experience 
and Activist Identity Construction in the Spanish Environmental Movement." Journal of Contemporary Ethnography 40(6):713-33.

Rupp, Leila and Verta Taylor. 1987. Survival in the Doldrums: The American Women's Rights Movement, 1945 to the 1960s. New York: Oxford University Press.

Snow, David A and Doug McAdam. 2000. "Identity Work Processes in the Context of Social Movements: Clarifying the Identity/Movement Nexus." Pp. 41-67 in Self, Identity, and Social Movements, Vol. 13, edited by Sheldon Stryker, Timothy Owens and Robert White. Minneapolis, MN: University of Minnesota Press.

Stryker, Sheldon and Richard Serpe. 1994. "Identity Salience and Psychological Centrality: Equivalent, Overlapping, or Complementary Concepts?". Social Psychology Quarterly 57(1):16-35.

Stryker, Sheldon. 2000. "Identity Competition: Key to Differential Social Moevment Participation." in Self, Identity and Social Movements, edited by Sheldon Stryker, Timothy Owens and Robert White. Minneapolis, MN: University of Minneapolis Press. Taft, Jessica. 2006. "“I'm Not a Politics Person”: Teenage Girls, Oppositional Consciousness, and the Meaning of Politics." Politics \& Gender 2(3):329-52.

Taft, Jessica. 2017. "Teenage Girls’ Narratives of Becoming Activists." Contemporary Social Science 12(1-2):27-39.

Taylor, Verta and Nancy Whittier. 1995. "Analytical Approaches to Social Movement Culture: The Culture of the Women’s Movement." Pp. 163-87 in Social Movements and Culture, edited by Hank Johnston and Bert Klandermans. Minneapolis, MN: University of Minnesota Press.

Terriquez, Veronica. 2015. "Intersectional Mobilization, Social Movement Spillover, and Queer 
Youth Leadership in the Immigrant Rights Movement." Social Problems 62(3):343-62.

Valocchi, Stephen. 2009. "The Importance of Being" We": Collective Identity and the Mobilizing Work of Progressive Activists in Hartford, Connecticut." Mobilization: An International Quarterly 14(1):65-84.

Valocchi, Stephen. 2013. "Activism as a Career, Calling, and Way of Life." Journal of Contemporary Ethnography 42(2):169-200.

Van Laer, Jeroen and Peter Van Aelst. 2010. "Internet and Social Movement Action Repertoires:

Opportunities and Limitations." Information, Communication \& Society 13(8):1146-71.

Weiss, Robert. 1995. Learning from Strangers: The Art and Method of Qualitative Interview

Studies. New York: Simon and Schuster.

White, Robert. 2010. "Structural Identity Theory and the Post-Recruitment Activism of Irish Republicans: Persistence, Disengagement, Splits, and Dissidents in Social Movement Organizations." Social Problems 57(3):341-70.

Whittier, Nancy. 2010. Feminist Generations: The Persistence of the Radical Women's Movement. Philadelphia, PA: Temple University Press.

\footnotetext{
${ }^{\mathrm{i}}$ Although we see an activist as someone who is involved in non-institutional politics, this did not influence our research methods or interview schedule. As we explain in this article, forms and amount of involvement vary in important ways as does how our respondents define who an activist is and whether they can be considered one.

ii Notably, although 91\% of Cortese's respondents identified as activists, activist identification was less clear for younger respondents. Of the eight respondents under twenty-five, only one (a staff member) emphatically identified as an activist (2015:225) indicating important variation within pre-existing literature on the subject.

iii Both interview sites were in the city, and so we cannot say whether respondents in other locations make different decisions regarding their activist identities. While our findings are
} 
consistent with other research on youth activism, Amy Binder and Kate Wood (2012)'s work on campus conservativism shows that activist cultures can vary in important ways across campuses. iv We received IRB approval for all interview materials. University student interviews were IRB exempt. High school student interviews were conducted under a separate study ID, and the student and a guardian signed IRB approval forms prior to being interviewed. We used a structured interview guide to ensure a consistent interview process. Many interviews were conducted by undergraduates who went through months of training on interviewing and our interview guide, including conducting mock interviews and receiving feedback.

${ }^{\mathrm{v}}$ We did not recruit for ideological diversity and we did not ask about partisanship. Several students discussed issues typically associated with more conservative beliefs like gun rights, supporting veterans, and religious activity, indicating that we had some ideological diversity. Although ideological differences may influence youth perceptions' of activist identities, we cannot assess this with our data; we hope future research pursues this in more depth.

${ }^{\text {vi }}$ We reminded respondents who hesitated to offer a definition that there was no wrong answer, and asked them to explain what the word meant to them. One respondent was asked these questions in reverse order. We code them as "missing."

vii Like previous studies on this subject (Bennett et al. 2013, Bobel 2007, Cortese 2015), we did not deliberately seek out respondents with "contested identities." Instead, their contested nature emerged from their responses to our questions about specific identities. Future research should deliberately pursue such identities to understand how they are constructed and their implications in more detail. We thank our reviewers for drawing our attention to this point.

viii Two respondents self-identified as activists after they were given a definition of activism to respond to (everyone else was asked to define it themselves) or were asked to define activism and then asked whether they self-identified as an activist. Both respondents were active with participatory politics or traditional volunteering, but not activism. We code both as "missing." We also do not find any evidence that non-identifiers-particularly highly engaged nonidentifiers — used euphemisms or alternative identities (i.e. “advocate” or "environmentalist”) to avoid identifying as activists We do find one respondent who claimed a more specific movement or organizational identity — gender equality activist — when asked if she identified as an activist. We coded her as identifying as an activist.

${ }^{\text {ix }}$ Five total respondents were not coded into one of these groups: three due to the question order issues mentioned in the footnotes above and two did not provide a generic or self-definition of activism because they left the interview before reaching these questions.

${ }^{x}$ Of course, intention to participate is does not guarantee future participation (Klandermans and Oegema 1987), but the variation in intent does highlight the potential impact of activist identity adoption for future engagement. Future research should explore this relationship in more detail. ${ }^{x i}$ All of these questions about respondents' future participation were phrased to gauge their willingness to continue to engage at their current level in the future. The questions did not ask whether they were willing to be more engaged. This meant that the highly engaged respondents were responding to whether they would continue to participate at the same level, and those who only signed online petitions were willing to continue to sign petitions. Further, non-active respondents - especially high school students - were often posed with hypothetical questions about their willingness to sign a petition, attend a rally, etc. 